\title{
Urgences
}

\section{L'âge mûr}

\section{Lévis Dumais}

Numéro 13, mars 1986

\section{Éclats d'atelier}

URI : https://id.erudit.org/iderudit/025218ar

DOI : https://doi.org/10.7202/025218ar

Aller au sommaire du numéro

\section{Éditeur(s)}

Urgences

\section{ISSN}

0226-9554 (imprimé)

1927-3924 (numérique)

Découvrir la revue

\section{Citer ce document}

Dumais, L. (1986). L'âge mûr. Urgences, (13), 41-44.

https://doi.org/10.7202/025218ar d'utilisation que vous pouvez consulter en ligne.

https://apropos.erudit.org/fr/usagers/politique-dutilisation/ 


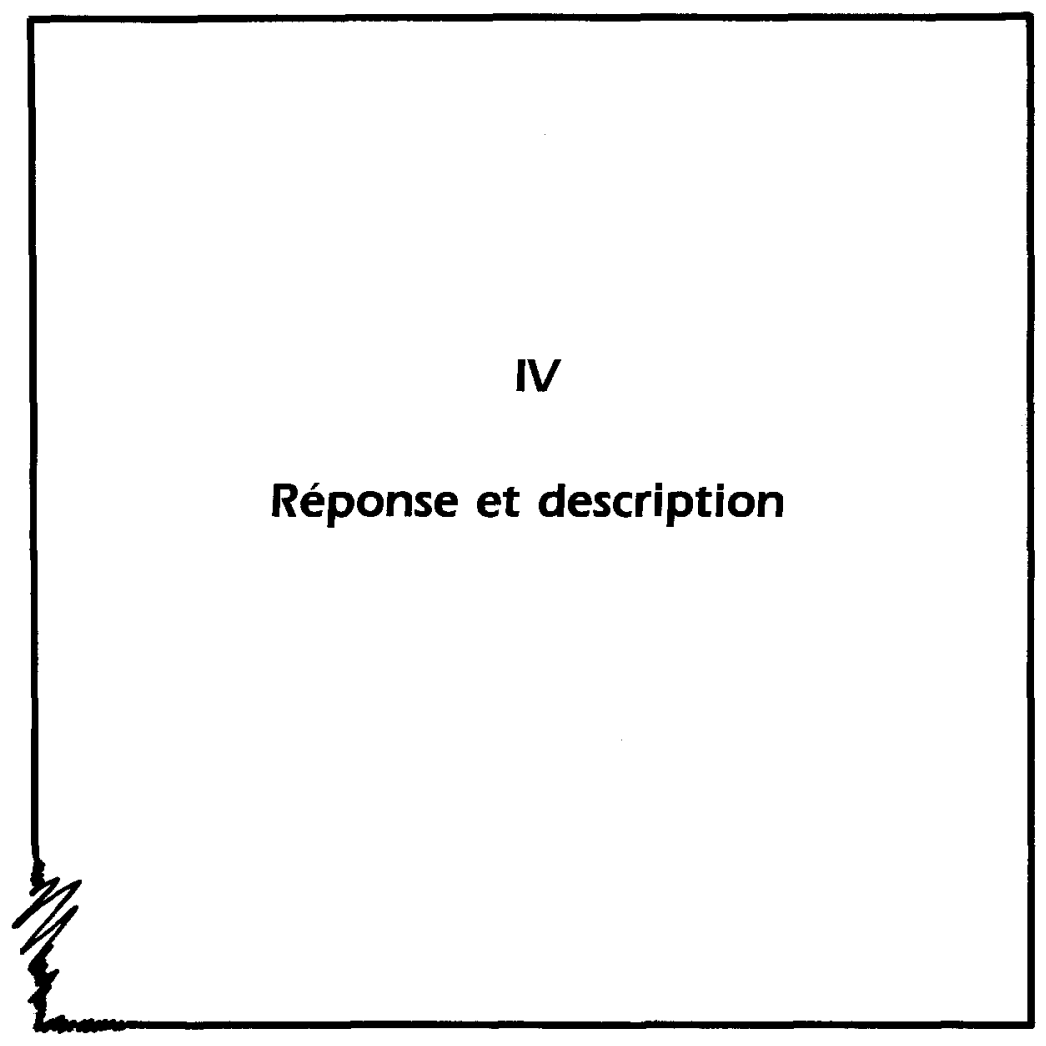




\section{Postulats: réponse et description}

Écrire un texte qui, par une description (enchâssée plus ou moins dans un bref récit), réponde à l'une ou l'autre des questions suivantes: "Étant donné un mur, que se passe-t-il derrière?" et "Quel est le plus long chemin d'un point à un autre?"

Description - voir Jean Ricardou: Problèmes du nouveau roman, coll. "Tel Quel", Paris, Seuil, 1967, p. 92 et ss.; Pour une théorie du nouveau roman. p. 33 et ss.

1. Jean Tardieu: Un mot pour un autre, Paris, Gallimard, 1951, p. 119 (voir pages suivantes pour plusieurs autres problèmes et travaux pratiques). 


\section{L'ÂGE MÛR Lévis Dumais}

Les décibels ne se comptaient plus. Des lumières de toutes les couleurs s'allumaient et s'éteignaient en tournoyant. N'en pouvant plus, quelques-uns étaient en transe et s'exhibaient au beau milieu de la place. On aurait dit qu'ils essayaient de se défaire du long ruban de fumée dans lequel ils étaient empêtrés. Dans cette atmosphère illusoire, on porte souvent plus attention aux regards et aux sourires qu'aux paroles. Le sien avait quelque chose d'ironique, ce genre de sourire qui semble vous dire: "Non merci, j'en ai assez!". Ça lui donnait un air suffisant. Malgré tout, sans même y réfléchir, elle avait répondu à ce sourire et, depuis vingt minutes déjà, ils se hurlaient des banalités. Comme il se rapprochait tout en parlant, un soupçon s'éleva en elle, soupçon qui se confirma lorsqu'il se pencha à son oreille pour lui crier un peu moins fort:

- Tu sais que tu m'plais beaucoup? As-tu dix-huit ans au moins? Tu comprends, à mon âge pis dans ma situation, j'voudrais pas...

J'le savais que ça viendrait, pensa-t-elle, ça fait pas vingt minutes qu'on jase pis il est déjà mûr pour la couchette. Amusons-nous.

- Inquiète-toi pas, mon pit, si t'as des problèmes avec moi, ça sera pas à cause de ça.

- Qu'est-ce que tu veux dire par là?

- Rien, rien...

Son sourire, sans disparaître, perdit quelque peu de son assurance. II jeta un regard circulaire et salua quelqu'un machinalement. II leva son verre, la regarda et lui sourit; mais elle le vit à travers la bière et il lui parut jaune. II reposa son verre, sans même avoir bu. Fouillant dans 
ses poches, il en sortit des cigarettes et un briquet qu'il fit tourner entre ses doigts après s'en être servi.

- T'as pas de maladies toujours?

- Ben non, ben non, mon pit! C'est juste que t'es en train d'aller un peu trop vite à mon goût. Tu sais, c'est pas parce que j'suis jeune que j'suis nounoune. C'est ça votre problème, les vieux: vous pensez qu'on vous doit tout parce que vous avez de l'expérience. Eh ben! j'vais t'dire une bonne chose, moi:j'ai peut-être pas ton âge, mais j'suis rendue où t'es rendu, pis en même temps. Understand, dad?

Ayant autant compris qu'un enfant de cinq ans auquel on aurait expliqué la théorie de la relativité, il ne prit même pas le temps de finir sa bière ou sa cigarette et s'en alla en pensant qu'il était peut-être fini le temps où les femmes se contentaient de dire oui ou non, et plus souvent oui que non. 